\title{
Comparative Study of Zinc and Probiotics versus Zinc Alone Therapy in Children with Acute Watery Diarrhea
}

\author{
Mst. Musarrat Sultana ${ }^{1}$, Md. Shafiqul Islam ${ }^{2}$, Shahana Akhter ${ }^{3}$ \\ Md. Belal Hossain ${ }^{4}$, Md. Sanaul Haque Mia ${ }^{5}$
}

\begin{abstract}
Objective: Diarrhea is a common problem in our country especially children. There were many treatment options for acute watery diarrhea in addition to oral rehydration saline for reducing the severity of acute watery diarrhea. The aim of this study was to compare the efficacy of zinc \& probiotics combination therapy to zinc alone therapy in reducing the severity of acute diarrhea.

Method: This was a randomized controlled trial type study, conducted at department of pediatrics Rajshahi Medical College Hospital from July 2014 to June 2016. A total of 110 numbers of children ages 6 months to 5 years with acute watery diarrhea were enrolled those who were fulfilled the selection criteria. They were divided into two groups. Group $A(n=55)$ received zinc-probiotics combination therapy and group $B \quad(n=55)$ received zinc only. Measurement of disease severity was based on the frequency of diarrhea (times/day) and duration of diarrhea (hours) after initial drug consumption.

Result: Among the study population $56 \%$ male $\& 44 \%$ female in group A and $58 \%$ male $\& 42 \%$ female in group B. Duration of acute watery diarrhea was significantly reduced in group $A$ than group $B(56.22$ versus 70.69 hours respectively), (P-0.002)and frequency of stool also reduced in group $A$ than group B(3.92 versus 7.15 times/day) on day 2 (P-0.002). Consistency of stool also improved in group $A$ than group $B$ [liquid stool12(21.8\%) versus $25(45.5 \%),(P-0.015)$ on day 1 , semi-liquid stool $4(8.2 \%)$ versus $16(30.8 \%)$, (P-0.004) on day 2, formed stool $29(52.73 \%)$ versus 16(29.09\%), P-0.004 on day 2 respectively].
\end{abstract}

Conclusion: Combination therapy was more effective in reducing the severity of acute watery diarrhea than zinc alone therapy in children.

Key words: Acute watery diarrhea, zinc, probiotic, outcome.

TAJ 2017; 30: No-2: 32-38

\section{Introduction}

Diarrheal disorders in childhood account for a large proportion (18\%) of childhood deaths, with an estimated 1.5 million deaths per year globally, making it the second most common cause of child deaths worldwide. ${ }^{[1-2]}$ The World Health
Organization (WHO) and UNICEF estimate that almost 2.5 billion episodes of diarrhea occur annually in children $<5$ year of age in developing countries, with more than $80 \%$ of the episodes occurring in Africa and South Asia (46\% and $38 \%$, respectively). Global mortality may be

1 Junior Consultant (Paediatrics), Upazila Health Complex, Gurudaspur, Natore.

2 Registrar, Department of Gastroenterology, Rajshahi Medical College Hospital, Rajshahi.

${ }^{3}$ Medical Officer, Department of Paediatrics, Rajshahi Medical College Hospital, Rajshahi.

4 Junior Consultant (Paediatrics), Rajshahi Medical College Hospital, Rajshahi.

5 Professor \& Head, Department of Paediatrics, Rajshahi Medical College, Rajshahi. 
declining, but the overall incidence of diarrhea remains unchanged at about 3.6 episodes per child-year. ${ }^{1} \quad$ Currently WHO recommends treatment with oral rehydration salts (ORS) and continued feeding for the prevention and treatment of dehydration, as well as zinc to shorten the duration and severity of the episodes. ${ }^{3}$ Probiotics are not recommended by WHO for the treatment of community-acquired acute diarrhea, though they are becoming increasingly popular in some country. ${ }^{4}$ Probiotics are non-pathogenic live microorganisms. When ingested, probiotics can survive passage through the stomach and small bowel. ${ }^{5}$ They compete with enteric pathogens for available nutrients and bacterial adhesion sites, increased the acidity of intestinal environment, synthesize compounds that destroy or inhibit pathogens and may stimulate the host immune response to invading pathogens. ${ }^{6}$ In previous studies have shown that benefits of probiotics on diarrhea in children may be strain and/or etiology specific. $^{7-9}$ A 2010 Cochrane systematic review of the use of probiotics for the treatment of acute diarrhea found a significant reduction in the mean duration of diarrhea (24.76 hours; 95\% CI 15.9133.61 hours) and stool frequency on the second day of treatment (mean difference 0.80; 95\% CI 0.45-1.14 .This probiotics also prevents rotavirusinduced diarrhea, and the recurrence of colitis. ${ }^{\mathbf{1 0}}$ Zinc has a direct effect on intestinal villous, brush border disaccharides activity and intestinal transport of water and electrolytes. Zinc also has a marked effect on $\mathrm{T}$ cell function and its supplementation improves immunity. Thus it may also reduce the severity of diarrhea. ${ }^{11}$ A study of ICDDRB on Zinc supplementation in children with cholera in Bangladesh reveals that more patients in the zinc group than in the control group recovered by two days (49\% v 32\%, P-0.032) and by three days (81\% vs.68\%, P-0.03). Zinc supplemented patients had $12 \%$ shorter duration of diarrhea than control patients (64.1 vs. 72.8 h, P$0.028) .{ }^{[12]}$ So we expect that combined therapy with zinc and probiotics will be more efficacious than zinc therapy alone. In this context our study is justifiable.

\section{Materials and Methods}

One hundred ten children aged 6 months to 5 years admitted in Rajshahi Medical College Hospital (RMCH) with acute watery diarrhea (AWD) during July 2014 to June 2016 were selected. This study was hospital based randomized controlled clinical trial (RCT) study. Patient who had diarrhea that has been treated for more than 3(three) days at home, dysentery, severe malnutrition, who has received any type of medication (antibiotics, antiprotozoal etc.) except fluid and zinc, septicemia or any other inflammatory diseases, any cardiac anomaly, immunodeficiency condition were excluded from this study. Immediately after getting admitted into hospital with AWD, patients meeting the inclusion criteria were selected for the study. The case was randomized \& purposively selected as group A (Probiotics plus zinc) and group B (Zinc alone).A consent formed is signed by the parents before initiating any treatment. In group A received one ample probiotics two times for 5 days and $20 \mathrm{mg}$ of zinc syrup daily for 10 days. In group B each patients received $20 \mathrm{mg}$ zinc syrup only for 10 days. On daily follow up presence of fever, vomiting, number of stool passed with consistency was recorded and sign of dehydration was assessed. ORS and IV cholera saline were given to the patient according to the need. We did not perform stool examination because of the high cost required. The cause of diarrhea was distinguished only by the stool consistency. Dysentery was characterized by acute diarrhea mixed with blood, while cholera and diarrhea caused by rotavirus was characterized by acute watery diarrhea. We suspected cholera if 1) symptoms occurred during known diarrheal outbreaks involving children and adult; or 2) frequent, voluminous, loose quickly led to severe dehydration with hypovolemic shock. Monitoring of the duration and frequency of diarrhea was done during hospitalization and after the patient was discharged. Toxicity and side effects relating to the administration of zinc and probiotics were also observed (nausea, vomiting, abdominal pain, and sepsis).We defined recovery from diarrhea as stool passed $<3$ times with normal consistency. Home 
monitoring was done by contacting the parents or caregivers by telephone.

All data were compiled and edited meticulously by thorough checking and rechecking. All omissions and inconsistencies were corrected and removed methodically. The results were collected, tabulated and statistically analyzed by using window based computer software device with statistical package for social science (SPSS-16). Patient characteristics were reported as means \pm standard deviations, medians (ranges), or $\mathrm{n} \mathrm{( \% )}$ as appropriate. t- test or were used for continuous variables and chi-squared test were used for categorical variables.
Results:

Mean age of group A and group B were almost similar $14.01 \pm 6.72$ and $13.31 \pm 8.02$. In group $\mathrm{A}$ male $56 \%$ \& female $44 \%$ and in group B male $58 \%$ \& female $42 \%$. Greater number of the patients was male in both groups $(56.36 \%$ vs. $58.18 \%)$.

In group A 20(36.36\%), 35(63.64\%) \& 3(5.45\%) children had no sign, some \& severe dehydration respectively. Vomiting was present in 38 (69\%) children and fever was recorded in 31(56.4\%)

Table-01: Baseline characteristics of study subject $(n=110)$ :

\begin{tabular}{lcc}
\hline Variables & $\begin{array}{c}\text { Group A (Zinc + Probiotics) } \\
(\mathbf{N}=\mathbf{5 5})\end{array}$ & $\begin{array}{c}\text { Group B (Zinc) } \\
\text { (N=55) }\end{array}$ \\
\hline Age & & $\mathbf{1 3 . 3 1 \pm 8 . 0 2}$ \\
Mean age \pm SD in month & $\mathbf{1 4 . 0 1} \pm \mathbf{6 . 7 2}$ & \\
Sex & & $32(58 \% 0$ \\
Male & $31(56 \%)$ & $23(42 \%)$ \\
Female & $24(44 \%)$ & \\
Feeding history & & $2(3.63 \%)$ \\
Breast feeding only & $1(1.81 \%)$ & 00 \\
Formula feeding & $1(1.81 \%)$ & $53(96.36 \%)$ \\
Complimentary food & $53(96.36 \%)$ & \\
Sanitation & & $44(80 \%)$ \\
Good & $48(87.27 \%)$ & $9(20 \%)$ \\
Poor & $7(12.73 \%)$ & \\
Mother's education & & $4(7.27 \%)$ \\
No education & $2(3.64 \%)$ & $9(16.36 \%)$ \\
Primary & $3(5.45 \%)$ & $33(60 \%)$ \\
SSC & $34(61.82 \%)$ & $7.64 \%)$ \\
HSC & $14(25.45 \%)$ & \\
Graduate+ & $2(3.64 \%)$ & \\
\hline
\end{tabular}




\begin{tabular}{lcc}
\hline Nutritional status & \\
Good & $15(27.3 \%$ & $20(36.4 \%)$ \\
Mild malnutrition & $32(58.2 \%)$ & $17(30.9 \%)$ \\
Moderate malnutrition & $8(14.5 \%)$ & $18(32.7 \%)$ \\
$\begin{array}{l}\text { Mean frequency of diarrhea } \\
\text { before treatment (times/day) }\end{array}$ & $\mathbf{3 7 . 7 8} \pm \mathbf{2 2 . 6 2}$ & $\mathbf{3 9 . 3 0} \pm \mathbf{1 9 . 9 3}$ \\
$\begin{array}{l}\text { Mean duration of diarrhea } \\
\text { before treatment (hours) }\end{array}$ & $\mathbf{3 0 . 0 2 \pm \mathbf { 1 1 . 8 7 }}$ & $\mathbf{2 8 . 1 3} \pm \mathbf{1 2 . 3 9}$ \\
$\begin{array}{l}\text { Degree of dehydration } \\
\text { No dehydration }\end{array}$ & & \\
Some dehydration & $20(36.36 \%)$ & $17(30.90 \%)$ \\
Severe dehydration & $35(63.64 \%)$ & $37(67.27 \%)$ \\
Mean Weight \pm SD (Kg) & $3(5.45 \%)$ & $1(1.81 \%)$ \\
\hline
\end{tabular}

children. In group B, 17(30.90\%), 37 (67.27\%) \& $1(1.81 \%)$ children had no sign, some \& severe dehydration respectively. Vomiting \& fever was in $40(72.7 \%)$ and $25(45.45 \%)$ patients respectively. From this table we observed that most of the patients had vomiting \& fever with AWD. Mean weight of group A was $8.6( \pm 1.57) \mathrm{Kg}$ \&group B was $8.5( \pm 2.16) \mathrm{Kg}$. Mean weight of both group were almost similar. Mean duration of diarrhea before enrollment about 38 hours among the patients of group A and 39 hours among the patients of group $\mathrm{B}$. That was not significant (Pvalue >0.05). Before enrollment mean stool frequency (no. of stool passed per day) were $30.02 \pm 11.87$ versus $28.13 \pm 12.39$ per day in group A \& group B respectively which was not statistically significant (P-value $>0.05$ ).

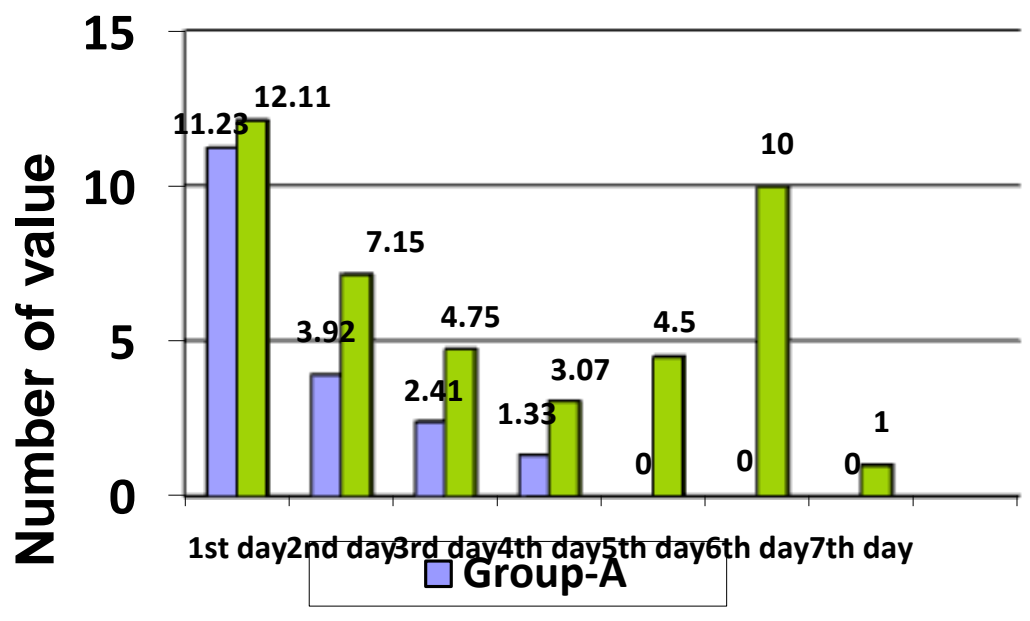

Figue-1: Gradual reduction of frequency on different days. 
Consistency of diarrhea also improved. Watery stool was present 12 (21.8\%) \& 25 (45.5\%) children on day 1 , (P- 0.015), semi-liquid stool was $4(8.2 \%) \& 16(30.8 \%)$ children on day 2 (P$0.004)$ in group A \& group B respectively. On the other hand (36.4\%) \&10 (18.2\%) children had loose stool on day 1 (P- 0.027) and 29 (52.73\%) \& 16 (29.09\%) had normal stool on day 2 in group A
\& group B respectively. Mean remission time of diarrhea (time required to form solid stool from watery stool) was $56.22 \pm 21.39$ vs. $70.69 \pm 26.29$ hours in group A \& group B respectively. Result of present study was statistically significant (P0.002).

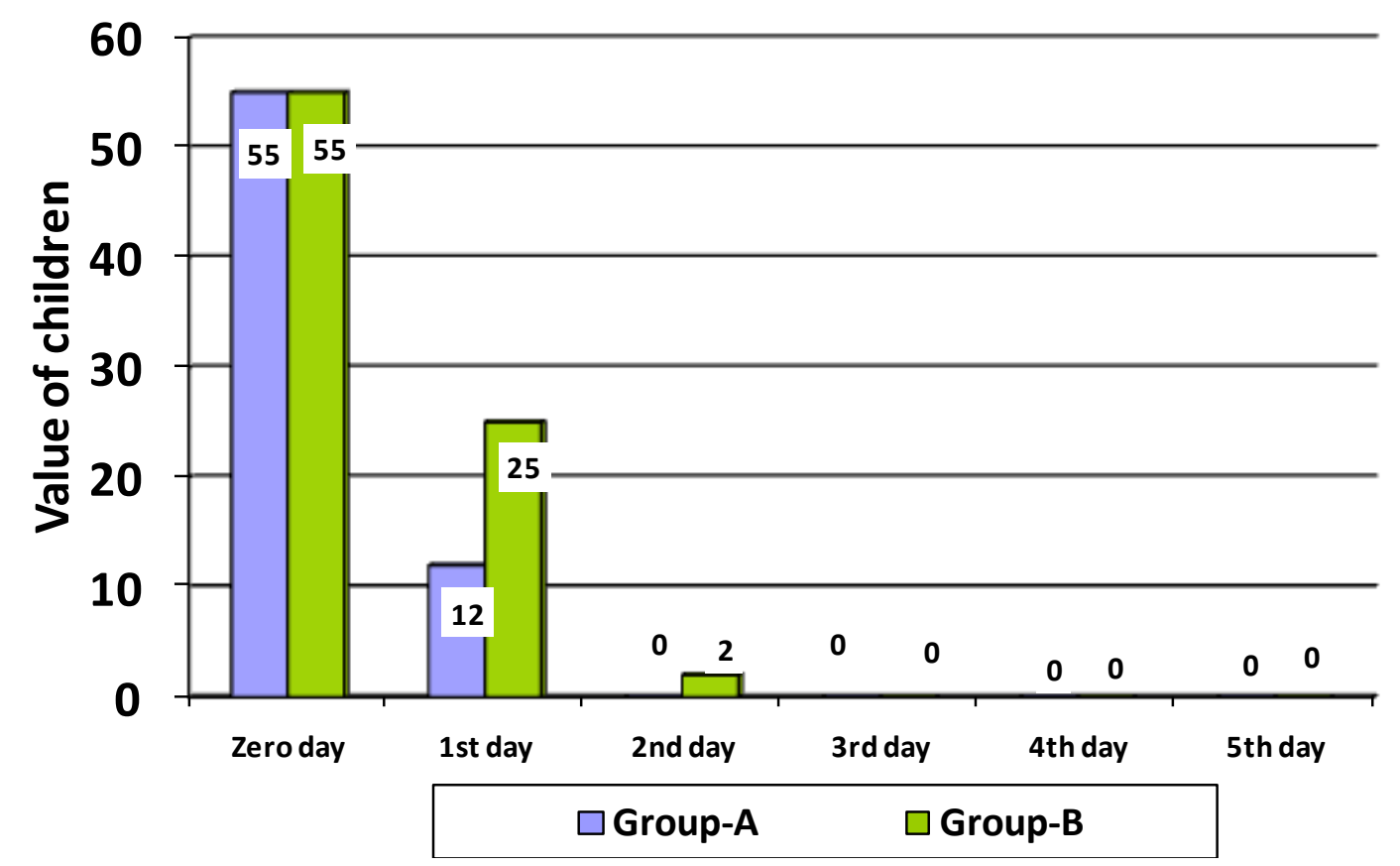

Figure 02: Gradual decrement of watery/liquid stool on different days.

Table-2: Duration of Hospital stay \&remission of diarrhea among study population

\begin{tabular}{llcl}
\hline Parameter & $\begin{array}{l}\text { Group A (Zinc }+ \\
\text { Probiotics) (n=55) }\end{array}$ & $\begin{array}{l}\text { Group B (Zinc) } \\
(\mathbf{n = 5 5 )}\end{array}$ & P-value \\
\hline & & & \\
Discharge from Hospital (Hours) & $32.11 \pm 15.08$ & $43.64 \pm 20.70$ & 0.001 \\
Remission time (Hours) & $56.22 \pm 21.39$ & $70.69 \pm 26.29$ & 0.002 \\
\hline
\end{tabular}




\section{Discussion:}

Diarrhea is a worldwide public health problem in pediatrics population, particularly so in developing countries. Introduction of oral rehydration therapy has provided great relief. In spite of this diarrhea still remains one of the leading causes of childhood morbidity \&mortality. Various modalities of interventions have been used in different parts of the world to improve the diarrheal mortality \& morbidity which include oral rehydration salt (ORS), cereal-based ORS, antibiotics, anti-diarrheal, antispasmodics \&antiemetic's. ${ }^{13}$ The search for the agents that can reduce the severity \& duration of diarrhea led to discovery of probiotics. Probiotics have been shown to be effective in varied clinical conditions ranging from infantile diarrhea, necrotizing enterocolitis, antibiotics associated diarrhea, relapsing Clostridium difficile colitis, Helicobacter pylori infection, inflammatory bowel disease to cancer. ${ }^{14}$ In this study the mean age of children with acute diarrhea was $14.01 \pm 6.72$ months in the combination group and $13.31 \pm 8.02$ months in the zinc group. Most of the patients (58.18\%\&60\%) are under 12 months in both groups. Previous epidemiological studies found that children with acute diarrhea were aged 0 to 12 months. ${ }^{15}$ There was another study done by Aggarwal et al. where mean age was $19.18 \pm 12.78$ months \&20.02 \pm 14.02 months in case \& control group respectively. ${ }^{16}$ Before admission, in this study, 20(36.36\%), 35(63.64\%) \& 3(5.45\%) children in group A and 17(30.90\%), 37 (67.27\%) \& $1(1.81 \%)$ children in group B had no, some \& severe dehydration respectively. Similar study done by Erdoganet al. where shown that $48 \%$ \& $52 \%$ children in probiotic 1(Saccharomyces boulardii) group, $44 \%$ \& $56 \%$ in probiotic 2(Bifidobacterium lactis) and 52\% \& $48 \%$ in control group (only oral rehydration) had no \& some dehydration that is more or less similar to thisstudy. ${ }^{17}$ Mean duration of diarrhea before treatment was $37.78 \pm 22.62$ hours in group A and $39.30 \pm 19.93$ hours in group B in our study. Aggarwal et al. (2014) reported mean duration of diarrhea before treatment was $52.08 \pm 30.48$ hours in probiotic group \& $59.52 \pm 30.72$ hours in control group. Duration of diarrhea before treatment was shorter than Aggarwal et al. study. In present study on an average each patient passed $30.02 \pm 11.87$ times of stool before treatment among the group A and $28.13 \pm 12.39$ times of stool in group B. In this study, length of hospital stay was shorter in combination group than zinc group which is similar to Hattaet al.study. ${ }^{18}$ In my study zinc-probiotics group complete remission was achieved within 56.22 \pm 21.39 hours which was faster (P-0.002) than that of zinc alone group (70.69 \pm 26.29 hours). This study also showed a significant improvement in frequency and consistency of stool \& reduction in duration of illness in patients who were given in combination therapy. Htwe et al. shown that stools had a normal consistency on day 3 in 38 (76\%) of 50 patients in the probiotic (S. boulardii) group compared with only 12 (24\%) of 50 in the control group $(\mathrm{P}=0.019) .{ }^{19}$ Similar studies conducted by Billooet al. Aggarwalet al. Azimet al. ${ }^{13,16,20}$ also reported that probiotics improved consistency of stool.

Limitation of this study were that the etiology of diarrhea was unknown and study was only admitted patients in the pediatric wards were enrolled which leads to selection bias.

\section{Conclusion:}

Acute watery diarrhea in children is one of the most common causes of childhood mortality and morbidity in developing countries including Bangladesh. Probiotics therapy in has been recently introduced as a treatment for acute watery diarrhea. In our country probiotics therapy in acute watery diarrhea is not commonly practiced. We conclude that, combination of probiotics \& zinc therapy is more effective in reducing the severity of acute diarrhea than zinc therapy alone.

\section{References}

1. Bhutta ZA, Kliegman RM, Beharmen RE, Schor MF, Stanton BF.Acute Gastroenteritis in Children. Nelson textbook of pediatrics, twentieth edition. Philadelphia: WB Saunders 2016; Chapter 340; $\mathrm{p}(1854-1874)$.

2. Liu L, Johnson HL, Cousens S, Perin J, Scott S, Lawn JE, et al. Global, regional, and national 
causes of child mortality: an updated systematic analysis for 2010 with time trends since 2000. Lancet, 2012; 379(9832):2151-2161.

3. WHO/UNICEF joint statement. Clinical management of acute diarrhea. New York, NY, and Geneva, Switzerland: The United Nations Children's Fund/World Health Organization 2004: $1-8$.

4. Allen SJ, Martinez EG, Gregorio GV, Dans LF, 2010.Probiotics for treating acute Infectious diarrhea. Cochrane Database Syst Rev, 2010; 11: CD003048.

5. Macfarlane GT, Cummings JH. Probiotics and prebiotics: can regulating the activities of intestinal bacteria benefit health? BMJ, 1999; 318(7189):9991003.

6. Vanderhoof JA, Young RJ. Use of probiotics in childhood gastrointestinal disorders. J Pediatr Gastroenterol Nutr, 1998; 27(3):323-332.

7. Dinleyici EC, Eren M, OzenM, Yargic ZA, Vandenplas $Y$. Effectiveness and safty of Saccharomyces boulardii for acute infectious diarrhea. Expert Opin Biol Ther, 2012; 12(4):395410.

8. Canani RB, Cirillo P, Terring ,Cesarano L, Spagnuolo MI, Vincenzo AD et al. Probiotics for treatment of acute diarrhea in children: randomized clinical trial of five different preparations. Department of pediatrics, University of Neples Federico II, Neples, Italy. BMJ research, 2007; Doi: 10.1136/bmj. 39272.581736.55.

9. Ritchie ML, Romanuk TN. A meta-analysis of probiotic efficacy for gastrointestinal diseases.PLoS One2012; 7(4):e34938.

10. Patrick J, Golden BE, Golden MHN, 1980. 'Leucocyte sodium transport and dietary zinc in protein energy malnutrition', Am J ClinNutr, 1980; 33:617-620.

11. UNICEF. State of the World's Children, New York: Oxford University Press,1991; pp 1-12.
12. ICDDRB. Zinc supplementation for the treatment of diarrhea moving from research to practice, 2014. Available from: http://www.mostproject.org.

13. Billoo AG, Memon MA, Khaskheli SA, Murtaza G, Iqbal K, Shekhani M S, Siddiqi A Q. Role of a probiotic (Saccharomyces boulardii ) in management and prevention of diarrhoea. World $\mathrm{J}$ Gastroenterol,2006; 12(28): 4557-4560.

14. Gupta, V. Grag, R. Probiotics. Indian J Med microbial.2009; 27: 202-209.

15. Nguyen TV, Le VanP, Huy C, Weintraub A. Diarrhea caused by rotavirus in children less than 5 years of age in Hanoi, Vietnam. J ClinMicrobiol.2004; 42:5745-50.

16. Aggarwal S, Upadhyay A, Shah D, Teotia N, Agarwal A \& JaiswalV. Lactobacillus GG for treatment of acute childhood diarrhea: An open labelled, randomized controlled trial. Indian J Med Res.2014; 139: 379-385.

17. Erdogan O, Tanyeri B, Torun E, Gonullu E, Arslan $H$, Erenberk $U$ and Oktem F, 2012. Clinical Study The Comparition of the Efficacy of Two Different Probiotics in Rotavirus Gastroenteritis in Children. Hindawi Publishing Corporation; Journal of Tropical Medicine, 2012; Volume, Article ID787240, 5 pages, doi:10.1155/2012/787240.

18. Hatta M, Supriatmo, Ali M, Sinuhaji AB, Hasibuan B, Nasution FL. Comparison of zinc-probiotic combination therapy to zinc therapy alone in reducing the severity of acute diarrhea. Paediatrica Indonesia.2011; Volume 51, January, number 1, page 1-6.

19. Htwe K, Yee KS, Tin M, and Vandenplas Y, 2008. Effect of Saccharomyces boulardiiin the Treatment of Acute Watery Diarrhea in Myanmar Children: A Randomized Controlled Study.Am. J. Trop. Med. Hyg, 2008;78(2), pp. 214-216.

20. AzimK, Sheikh TS, Khan SN, 2014.Efficacy of Probiotics (Sacchromycesbulardii) in Acute Watery Diarrhoea in Children. J. Rawalpindi Med Coll (JRMC), 2014; 18(2):213-215. 